\title{
Impact of genetic progress on the profits of dairy farmers
}

\author{
D. Roibas ${ }^{1}$ and A. Alvarez \\ Department of Economics, University of Oviedo, Oviedo 33071, Spain
}

\begin{abstract}
This paper analyzes the role that genetic progress may play in improving profits of dairy farms. A novel data set of Spanish commercial dairy farms including management data and cow indices of genetic merit for production and nonproduction traits was used. In the empirical section, a frontier production function that included a farm genetic index for milk yield was estimated. To evaluate the full effect of genetics on farm profit it was necessary to consider the fact that feed intake increases with cows' genetic improvement. Results show that the increase in profits corresponding to the average genetic progress during the sample period is equivalent to a $5 \%$ increase in income from milk sales. Managerial ability plays an important role in exploiting genetics. Optimal management increases the return of genetics by $22 \%$ compared with farms with average management in the sample.
\end{abstract}

Key words: genetic merit, profit, frontier production function

\section{INTRODUCTION}

Major changes in the Common Agricultural Policy introduced by the Mid-Term Review (Commission of the European Communities, 2002) pose new challenges to dairy farmers in the European Union. In particular, the reduction in the intervention prices of butterfat and skimmed powdered milk is expected to produce a decline in farm-level milk prices, which in turn will cause a decrease in the income of dairy farmers. In fact, despite the spike in milk prices that took place in 2007-2008, the reduction of the intervention level and the current decrease in demand have caused European Union prices to fall below 2003 levels. The Commission of the European Communities predicts that prices will be "somewhat above the milk equivalent support price for milk ... which is much lower than before the 2003 reform" (Commission of the European Communities, 2009). In this environment, dairy farmers need to improve the profitability of their farms to remain in business, possibly through the use of improved genetic breeds.
It is widely accepted that tremendous genetic improvements have occurred in the dairy cattle population in recent decades. In Spain, in particular, the genetic index (GI) of milk production has increased by 525 $\mathrm{kg}$ per lactation between 1999 and 2006 (CONAFE, 2009). This progress has been mainly due to the availability of genetically top sires, the widespread adoption of artificial insemination, and the introduction of new technologies such as embryo transfer.

Some papers have studied the relationship between profits and genetic merit using a weighted average of the genetic merit of the sires used in the artificial insemination process on the farms (Weersink et al., 1991; Steine et al., 2008). The paper by Lawson et al. (2004) investigated the negative effect (increased production diseases) on milk yield of one-sided genetic selection. However, no published papers specifically estimate a milk production function while adjusting for differences in genetic levels of cows across farms. The absence of farm management databases including enough detailed economic information-on outputs and inputs and their prices, as well as real estate and equipment valuations used by farms - along with cow GI has precluded economic models of dairy production from explicitly accounting for the profitability that farmers are able to extract from genetics. This paper contributes to filling the gap in research by using a novel data set of Spanish dairy farms that includes sufficient information to evaluate economically the effect of genetics on farmers' profits.

The main objective of this study was to calculate the contribution of genetic progress to the profits of dairy farmers using the production function approach. The production function framework, which includes a farm GI for milk yield, allows us to calculate the increase in milk production associated with a change in genetic level. Once the contribution of genetic progress to farm production is estimated, it is possible to evaluate its effect on farm profits.

\section{MATERIALS AND METHODS}

\section{Data}

Received February 3, 2010.

Accepted June 1, 2010.

${ }^{1}$ Corresponding author: droibas@uniovi.es
A key feature of this paper is the combination of 2 data sets. The first was a set of farm management 
Table 1. Summary statistics of the dairy farms $(\mathrm{n}=83)$

\begin{tabular}{lcccc}
\hline Item & Mean & SD & Minimum & Maximum \\
\hline Milk yield (L/herd per yr) & 300,105 & 149,496 & 64,298 & 773,632 \\
Labor (man-equivalent units ${ }^{1}$ /herd per yr) & 2.04 & 0.55 & 1 & 3.50 \\
Cows/herd & 40 & 16 & 11 & 88 \\
Concentrates (kg/herd per yr) & 148,869 & 81,547 & 38,370 & 431,740 \\
Forage expenses (€/herd per yr) & 21,824 & 14,565 & 1,397 & 95,573 \\
Animal expenses (€/herd per yr) & 10,661 & 6,809 & 801 & 40,449 \\
Genetic index for milk yield (kg/herd per yr) & 160 & 160 & -199 & 671 \\
\hline
\end{tabular}

${ }^{1}$ Full-time adult employees per year.

records that contain data on milk production as well as inputs used by the farms. The second data set came from the Spanish Dairy Herd Improvement Association (CONAFE) and contained GI of production and nonproduction traits at the cow level. The sample was taken from 83 Spanish dairy farms during the period from 1999 to 2004. All farms represented in the sample were located in northern Spain and used exclusively Holstein-Friesian cows. Because some farms were not monitored for the entire period, the final sample was composed of 450 observations. Before analyzing the main characteristics of the farms in the sample, a brief description of the GI used in the empirical analysis is warranted.

The GI for milk yield included in the database is an estimate of genetic merit that is conceptually similar to those used in other countries. The indices are calculated for bulls and cows using the animal model (Gengler et al., 1999). Each GI is given in the units used to measure the trait. For example, the GI for milk yield is reported in kilograms of milk per lactation. The GI are recalculated for each cow twice per year. This recalculation procedure allows the accuracy of the genetic merit estimate to be improved. Consequently, for each animal, the latest and most precise evaluation available is used for the whole sample period. The GI of each herd is calculated as the arithmetic mean of cows' GI.

Table 1 reports some descriptive statistics of the dairy farms in the sample during the sampling period. From Table 1, it is noted that the average herd size could be considered small compared with dairy farms in other countries. In 2003, the average herd size was 78 cows in the United Kingdom, 75 in Denmark, and 59 in the Netherlands (Eurostat, 2010). However, farms in the sample were slightly larger than the average farm in this geographical region of Spain, which was 37 cows in 2004 (SADEI, 2009). Differences among farms are important because the standard deviation of farm production is $50 \%$ of the mean.

Table 2 shows some yearly descriptive statistics of the herds' GI for milk yield. From the trend shown in Table 2 , it is clear that farmers were trying to improve their herds' genetic merit because the average GI increased continuously during the sampling period.

In a preliminary analysis of the profitability of genetics, the farms were classified into 2 genetic groups, high and low, using the average GI for milk yield in each farm. Every year, each farm was assigned to the high (low) genetic group if its GI was above (below) the sample mean. Furthermore, the average milk yield, sales per cow, variable cost per cow (i.e., feed, breeding, veterinary and milking expenses), and gross margin (GM) or short-term profit (i.e., milk sales minus variable costs) were calculated for each genetic group. Table 3 shows that the high genetic group was associated with higher income per cow than the low genetic group because of higher milk production per cow. Gross margin per cow decreased from 2001 to 2004 because of a decrease in milk price from $€ 0.362 / \mathrm{L}$ in 2001 to $€ 0.322 / \mathrm{L}$ in 2004 . On the other hand, variable costs per cow were higher for the high genetic group because genetically better cows consume larger rations (see Veerkamp, 1998; Steine et al., 2008) and may have health problems more frequently (Heringstad et al., 2003). As the income advantage prevails over the variable cost increase, high genetic group cows seem to be more profitable than low genetic group cows.

However, this preliminary analysis did not allow us to conclude that the differences in the genetic quality of the herds were the only cause of the observed economic advantage of the high genetic group. Other differences found in the farms could contribute to the different profitability of the herds. Thus, it was necessary to de-

Table 2. Summary statistics of the average genetic index for milk yield in all herds by year

\begin{tabular}{lrrrc}
\hline Year & Mean & SD & Minimum & Maximum \\
\hline 1999 & -24 & 101 & -199 & 348 \\
2000 & 54 & 122 & -184 & 479 \\
2001 & 117 & 109 & -117 & 552 \\
2002 & 186 & 105 & -57 & 448 \\
2003 & 291 & 127 & 31 & 671 \\
2004 & 378 & 106 & 136 & 669 \\
\hline
\end{tabular}


Table 3. Farm economic performance by cow genetic level group

\begin{tabular}{|c|c|c|c|c|}
\hline Year/group & $\begin{array}{l}\text { Milk yield } \\
\text { (L/cow) }\end{array}$ & $\begin{array}{l}\text { Milk sales, } \\
(€ / \text { cow })\end{array}$ & $\begin{array}{c}\text { Variable cost } \\
(€ / \text { cow })\end{array}$ & $\begin{array}{l}\text { Gross margin } \\
(€ / \text { cow })\end{array}$ \\
\hline \multicolumn{5}{|l|}{1999} \\
\hline Low genetics & 6,544 & 2,227 & 1,264 & 962 \\
\hline High genetics & 7,331 & 2,564 & 1,544 & 1,020 \\
\hline \multicolumn{5}{|l|}{2000} \\
\hline Low genetics & 6,857 & 2,321 & 1,347 & 974 \\
\hline High genetics & 7,591 & 2,567 & 1,593 & 975 \\
\hline \multicolumn{5}{|l|}{2001} \\
\hline Low genetics & 6,769 & 2,450 & 1,398 & 1,052 \\
\hline High genetics & 7,800 & 2,820 & 1,652 & 1,168 \\
\hline \multicolumn{5}{|l|}{2002} \\
\hline Low genetics & 7,236 & 2,322 & 1,512 & 809 \\
\hline High genetics & 7,828 & 2,525 & 1,596 & 929 \\
\hline \multicolumn{5}{|l|}{2003} \\
\hline Low genetics & 7,235 & 2,312 & 1,511 & 802 \\
\hline High genetics & 7,808 & 2,510 & 1,586 & 923 \\
\hline \multicolumn{5}{|l|}{2004} \\
\hline Low genetics & 7,484 & 2,410 & 1,617 & 793 \\
\hline High genetics & 7,855 & 2,546 & 1,658 & 888 \\
\hline
\end{tabular}

velop an empirical model that allowed the contribution of genetics to farm profit to be properly estimated.

\section{Frontier Production Function}

The empirical analysis used the well-known concept of production function; that is, a mathematical description of the relationship between the output produced and the quantities of inputs used in the production process. Other methods, such as profit functions (used in Steine et al., 2008), are not well-suited to the data in this sample because the only input fully bought in the market is concentrates, the remaining inputs being at least partially produced on the farm.

A production frontier approach was used to evaluate the importance of optimal management on the productivity of genetics. This method has been previously used to analyze dairy production (Tauer, 2001; Lawson et al., 2004; Cabrera et al., 2010). A production frontier gives the maximal attainable output for any combination of inputs and is associated with an optimally managed farm. Thus, using this approach it is possible to estimate the expected production corresponding to an average managed farm as well as the maximum potential production associated with optimal management (Kumbhakar and Lovell, 2000), allowing, therefore, an evaluation of the importance of optimal (efficient) management practices in extracting the full value from genetic improvements.

Production frontiers correspond to a typical production function that is augmented with an additional error term that accounts for the possibility that farms do not employ technology in an efficient way. This term, which represents the extent of technical inefficiency in a farm, is modeled as a random component, giving rise to the concept of stochastic production frontier (Aigner et al., 1977):

$$
y_{i t}=f\left(x_{i t}\right) \cdot e^{\varepsilon_{i t}} \text {, and } \varepsilon_{i t}=v_{i t}-u_{i t},
$$

where $y_{i t}$ is output of farm $i$ in period $t, x_{i t}$ is a vector of inputs, $f\left(x_{i t}\right)$ represents the technology, and $\varepsilon_{i t}$ is a composed error term. The component $v_{i t}$ is a standard error term that captures statistical noise and other stochastic shocks affecting production such as weather, diseases, and so on. Production losses caused by bad management are captured by the component $u_{i t}$, which is a nonnegative random term. This component plays a key role in defining the technological frontier in such a way that when $u_{i t}=0$, the farm is optimally managed and, thus, considered technically efficient. On the other hand, when $u_{i t}>0$, the farm is said to be technically inefficient. Therefore, it is possible to define a technical efficiency (TE) index as the ratio between actual output $\left(y_{i t}\right)$ and maximum feasible output $\left(y_{i t}{ }^{*}\right)$ :

$$
T E_{i t}=\frac{y_{i t}}{y_{i t} *}=\frac{f\left(x_{i t}\right) \cdot e^{\left(v_{i t}-u_{i t}\right)}}{f\left(x_{i t}\right) \cdot e^{v_{i t}}}=e^{-u_{i t}} .
$$

Because the $u_{i t}$ component takes only zero or positive values, $y_{i t}$ is always equal to or lower than $y_{i t}{ }^{*}$. Thus, the technical efficiency index is bound between 0 and 1 . Technical efficiency index allows, then, the influence of management in extracting the maximum productivity from genetics to be evaluated: the better the management, the closer the technical efficiency index is to 1 . 


\section{Model Specification}

Because the true production function is unknown, a good empirical approximation is necessary. Linear models are not used in economic analyses of the technology used by profit maximizing farms because the first-order derivatives are constant, meaning that the contribution of an additional unit of each factor, the so-called marginal productivity, is constant. However, it is widely recognized that the marginal productivity of an input is not constant. For example, the increase in milk due to the use of one additional kilogram of feed (i.e., the marginal productivity of feed) will depend on the amount of feed currently used.

To allow for flexibility to relevant technological characteristics, a flexible functional form must be used (Chambers, 1988). Most of the flexible functional forms can be understood as second-order Taylor approximations to the true production function. The translog functional form (Christensen et al., 1973), which is a second-order Taylor approximation in natural logarithms, was chosen for this study. This functional form is frequently used to model dairy production (Alvarez and Arias, 2004; Lawson et al., 2004). Including a GI for milk yield as an explanatory variable, the equation to be estimated becomes

$$
\begin{aligned}
\ln y_{i t} & =\beta_{0}+\sum_{j=1}^{5} \beta_{j} \ln x_{j i t}+\frac{1}{2} \sum_{j=1}^{5} \sum_{k=1}^{5} \beta_{j k} \ln x_{j i t} \ln x_{k i t} \\
& +\gamma_{0} \ln z_{i t}+\frac{1}{2} \gamma_{00}\left(\ln z_{i t}\right)^{2}+\sum_{j=1}^{5} \gamma_{0 j} \ln z_{i t} \ln x_{j i t}[3] \\
& +\sum_{t=2000}^{2004} \beta_{t} D_{t}+\varepsilon_{i t}
\end{aligned}
$$

$$
\text { where } \begin{aligned}
\varepsilon_{i t} & =v_{i t}-u_{i t}, \\
v_{i t} & \sim N\left(0, \sigma_{v}^{2}\right), \text { and } \\
u_{i t} & \geq 0,
\end{aligned}
$$

where it was assumed that dairy farms produced milk using 5 inputs: labor $\left(x_{1 i t}\right)$, which includes family labor as well as hired labor and is measured in manequivalent units; that is, a full-time adult employee for a year; cows $\left(x_{2 i t}\right)$, defined as the number of adult cows in the herd; concentrates $\left(x_{3 i t}\right)$, measured in kilograms; forage expenses $\left(x_{4 i t}\right)$, defined as forage purchases plus the costs of seeds, fertilizers, machinery, fuel and land; and animal expenses $\left(x_{5 i t}\right)$, defined as livestock supplies, breeding and veterinary expenses. All the monetary variables were measured in 2007 Euro $(€)$. The GI for milk yield $\left(z_{i t}\right)$ was used as a control variable and was included as another input. Because the GI can take on negative values and equation [3] requires a log-transformation, a constant equal to the average production per cow minus the average GI (which results in $7,200 \mathrm{~kg}$ of milk) was added to the GI, making all of them positive. This transformation allows for a clear interpretation of the estimated coefficients by relating the GI (which are associated with differences in production with respect to the average cow in reference year 2000) to milk produced per cow. $D_{t}$ are time dummy variables that take value 1 in the year indicated by the subscript and zero otherwise, and are expected to capture any timespecific effect common to all farms (such as technical change). The effect of year 1999 is represented in the intercept $\left(\beta_{0}\right)$. The error component $v_{i t}$ was assumed to follow a normal distribution with zero mean, and the nonnegative component $u_{i t}$ was assumed to follow a truncated normal distribution with mode $\mu$ and standard deviation $\sigma_{u}$. Finally, $\beta_{j}, \beta_{j k}, \beta_{t}, \gamma_{0}, \gamma_{00}$, and $\gamma_{0 j}$ are the parameters to be estimated.

Before proceeding to the estimation procedure, the explanatory variables were divided by their sample geometric mean. This transformation induces that the first-order parameters, those corresponding to the linear (in logarithm) terms of the equation, show the output elasticities with respect to inputs; that is, the percentage change in milk output when the corresponding input increases by $1 \%$. From the estimation of the output elasticities, it is possible to calculate the marginal productivity of genetics; that is, the increase in milk production if the GI goes up by $1 \mathrm{~kg}$. The output elasticity of genetics $\left(\gamma_{0}\right)$ is multiplied by estimated milk production and divided by the GI of the representative farm. This calculation is made for both a fully efficient farm and a farm with average technical efficiency.

$$
\begin{aligned}
& \text { Efficient farm: } \frac{\partial y}{\partial z}=\gamma_{0} \frac{f(\tilde{x}, \tilde{z})}{\tilde{z}} \\
& \text { Average farm: } \frac{\partial y}{\partial z}=\gamma_{0} \frac{f(\tilde{x}, \tilde{z})}{\tilde{z}} e^{E\left[-u_{i t}\right]},
\end{aligned}
$$

where $\tilde{x}$ is a vector representing the sample geometric mean of inputs and $\tilde{z}$ is the GI sample geometric mean. The expectation of technical efficiency $E\left[-u_{i t}\right]$, corresponding to a truncated normal distribution of $u_{i t}$, is calculated using the following expression (Stevenson, 1980):

$$
E\left[-u_{i t}\right]=-\left[\mu+\sigma_{u} \frac{\varphi\left(-\frac{\mu}{\sigma_{u}}\right)}{1-\Phi\left(-\frac{\mu}{\sigma_{u}}\right)}\right],
$$


where $\varphi$ represents the standard normal density function and $\Phi$ is the standard normal distribution function.

Equation [3] was estimated by maximizing the likelihood of the composed error term $\varepsilon_{i t}$, as shown in Stevenson (1980) using the statistical program Stata (Stata Corp., College Station, TX).

\section{Profit Calculation}

To assess the profitability of genetics, a simulation analysis was carried out. Gross margin was calculated for the average farm in the sample under 2 different scenarios. In the first scenario, the farm was assumed to use a herd with genetic merit equal to the sample mean in $2004\left(z^{04}\right)$, whereas in the second scenario, the herd GI was set equal to the sample mean in $1999\left(z^{99}\right)$. In the analysis, genetics is expected to influence farmers' profits in 2 ways: first, through its direct effect on milk production (better cows produce more milk even if feeding is held constant), and second, by an indirect contribution due to the increase in feed intake associated with cows with higher genetic merit. Defining GM as farm revenues minus variable costs, equation [6] resumes the aforementioned relationships between genetics and farmers' GM:

$$
G M=P \times f[z, C(z), F(z), x]-[C E(z)+F E(z)+O V C],
$$

where $P$ is milk price, $f[\cdot]$ is milk production, $z$ is the GI, $C$ represents the kilograms of concentrates, $F$ is quantity of forage, $x$ is a vector of the other inputs in milk production (labor, cows, and animal expenses), $C E$ is concentrate expenses, $F E$ is forage expenses, and $O V C$ represents other variable costs. Because the available data do not contain information about forage consumption, forage expenses are used as a proxy variable for forage quantity.

Note that in equation [6] concentrates and forage are considered to depend on the genetic quality of the herd. Thus, to compute expression [6], it was necessary to estimate the expected value of forage expenses and concentrates use depending on the genetic merit of the herd. Assuming that feed intake, in per-cow terms, follows a linear relationship with genetic merit, the equations to be estimated are:

$$
\begin{gathered}
C_{C O W}=\alpha_{C}+\beta_{C} z+e_{C}, \\
F E_{C O W}=\alpha_{F E}+\beta_{F E} z+e_{F E},
\end{gathered}
$$

where $C_{C O W}$ is concentrates per cow, $F E_{C O W}$ is forage expenses per cow, $\alpha$ and $\beta$ are the parameters to be estimated, and $e_{C}$ and $e_{F E}$ are the corresponding error terms.

To calculate the effect of genetics on milk production, a farm using an endowment of labor $\left(\bar{x}_{1}\right)$, cows $\left(\bar{x}_{2}\right)$, and animal expenses $\left(\bar{x}_{5}\right)$ equal to the sample mean was considered. Results obtained from solving equations [7] and [8] were used to calculate concentrate consumption $\left(x_{3}^{04}\right.$ and $\left.x_{3}^{99}\right)$ and forage expenses $\left(x_{4}^{04}\right.$ and $\left.x_{4}^{99}\right)$ under the 2 scenarios of the simulation analysis $\left(z^{04}\right.$ and $\left.z^{99}\right)$. These values were plugged into the estimated production frontier to calculate the contribution of genetic progress to milk production during the sampling period:

$$
\begin{aligned}
& y_{E F}^{04}=f\left(\bar{x}_{1}, \bar{x}_{2}, x_{3}^{04}, x_{4}^{04}, \bar{x}_{5}, z^{04}\right) \\
& y_{E F}^{99}=f\left(\bar{x}_{1}, \bar{x}_{2}, x_{3}^{99}, x_{4}^{99}, \bar{x}_{5}, z^{99}\right) \\
& y_{A F}^{04}=f\left(\bar{x}_{1}, \bar{x}_{2}, x_{3}^{04}, x_{4}^{04}, \bar{x}_{5}, z^{04}\right) \cdot e^{E\left[-u_{i t}\right]}, \\
& y_{A F}^{99}=f\left(\bar{x}_{1}, \bar{x}_{2}, x_{3}^{99}, x_{4}^{19}, \bar{x}_{5}, z^{99}\right) \cdot e^{E\left[-u_{i t}\right]},
\end{aligned}
$$

where $y_{E F}^{t}$ is the expected milk production for an efficient farm with genetic quality corresponding to year $t$ and $y_{A F}^{t}$ is the expected production for a farm with average technical efficiency.

Once the full effect of genetics on milk production is calculated, the effect of genetic progress on dairy farm GM can be assessed. Using the results obtained from equation [9] it is possible to evaluate expression [6] and obtain the associated GM. Expression [10] resumes GM calculation:

$$
\begin{aligned}
& G M_{E F}^{04}=P \times y_{E F}^{04}-W C \times x_{3}^{04}-x_{4}^{04}, \\
& G M_{E F}^{99}=P \times y_{E F}^{99}-W C \times x_{3}^{99}-x_{4}^{99}, \\
& G M_{A F}^{04}=P \times y_{A F}^{04}-W C \times x_{3}^{04}-x_{4}^{04}, \\
& G M_{A F}^{99}=P \times y_{A F}^{99}-W C \times x_{3}^{99}-x_{4}^{99},
\end{aligned}
$$


Table 4. Estimation of the stochastic production frontier function with models excluding and including cow genetic index (GI)

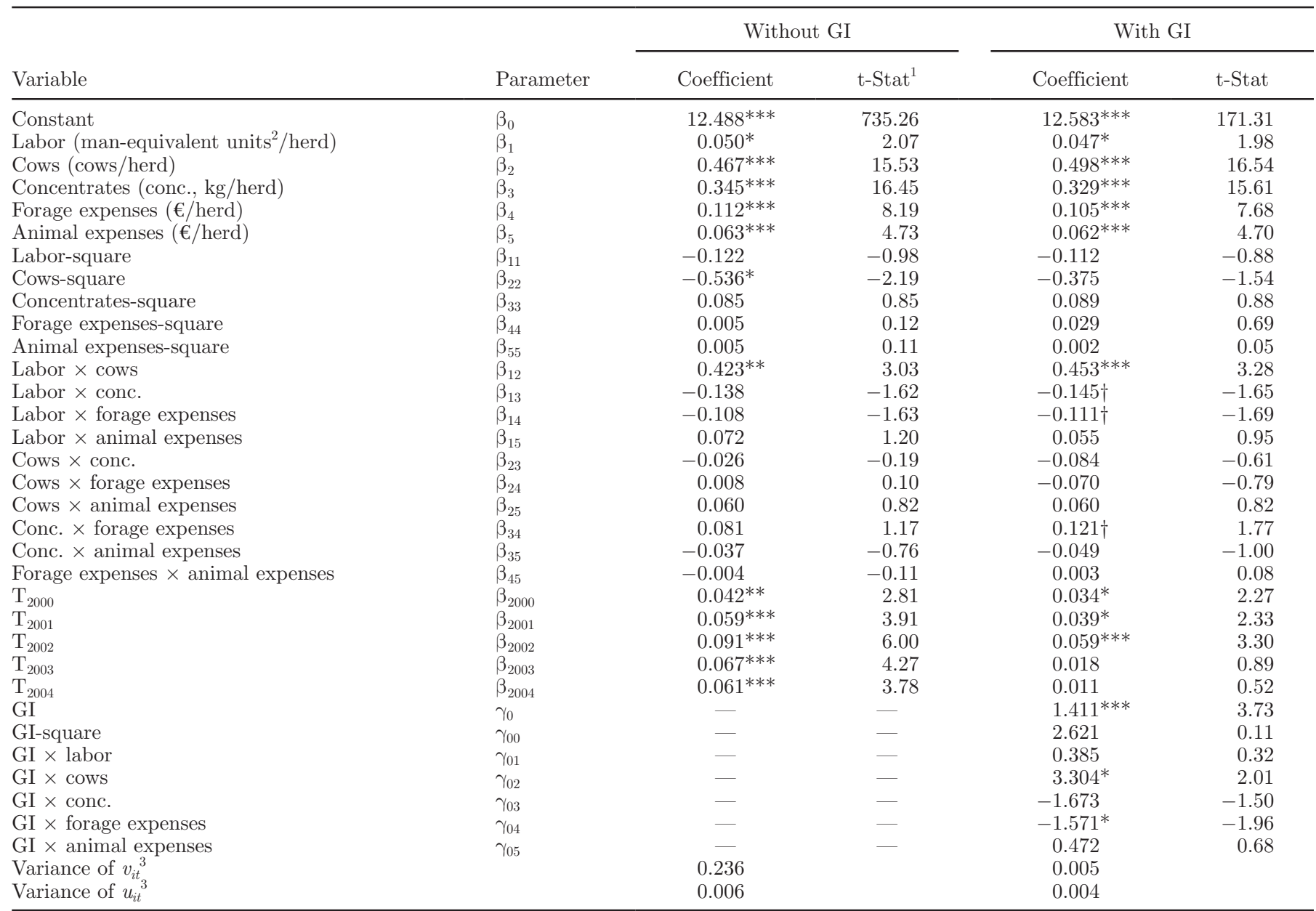

${ }^{1}$ t Student statistic.

${ }^{2}$ Full-time adult employees for a year.

${ }^{3}$ The component $v_{i t}$ is a standard error term that captures statistical noise and other stochastic shocks affecting production such as weather, diseases, and so on. Production losses caused by bad management are captured by the component $u_{i t}$, which is a nonnegative random term.

$\dagger P<0.10 ;{ }^{*} P<0.05 ;{ }^{* *} P<0.01 ;{ }^{* * *} P<0.001$.

where $P$ and $W C$ are, respectively, the sample average prices of milk and concentrates in 2004 .

\section{RESULTS AND DISCUSSION}

To assess the effect of the GI, equation [3] was also solved excluding GI. Results of the 2 models are presented in Table 4; both estimations are quite similar. The main differences in common parameters are found in coefficients for the time effects. In the estimation without genetics these coefficients are positive and different from zero $(P<0.01)$, whereas the last 2 parameters are not significant in the estimation that includes genetics. In addition, coefficients for the model with the GI are generally lower compared with those from the model without GI.
Time effects account for the effect on production of factors common to all farms and that were not incorporated into the estimated equation; hence, when GI were excluded from the analysis, these parameters may also capture the effect of the average genetic progress. Therefore, differences among the parameters in the 2 models suggest that technological change in dairy farming during the sampling period was due in part to genetic improvement. The contribution of other factors at the end of the period was marginal due to the nonsignificance of the time effects in the estimation including GI. Thus, data with both cross-section and time dimensions allow the sources of technological progress to be analyzed, with genetic improvement being its main component. 
The coefficient $\left(\gamma_{0}\right)$ of GI shows that genetics had an important direct contribution to the productivity of dairy farms $(P<0.001)$. The parameter capturing the interaction of genetics with number of cows was also found to be positive $(P<0.05)$, indicating that the output elasticity of genetics increased with herd size. Therefore, the increase in production per cow due to genetic progress was larger on large farms than on small farms.

The obtained output elasticities were similar to those found by Lawson et al. (2004). The largest elasticity was that related to the number of cows $\left(\beta_{2}\right.$ in Table 4$)$, which showed a value around 0.5 in both studies. The output elasticity of forage $\left(\beta_{4}\right)$ was also similar in both studies. The elasticity with respect to concentrates $\left(\beta_{3}\right)$ was almost double in this study compared with that in Lawson et al. (2004). This finding could be caused by differences in feeding and breeds of cows. Animals in Lawson et al. (2004) consumed, on average, 2,152 $\mathrm{kg}$ of concentrates per cow per year, whereas in this study average concentrate consumption was $3,722 \mathrm{~kg}$. Furthermore, only $57 \%$ of the cows in Lawson et al. (2004) were Holstein-Friesian, whereas all the cows in our sample were Holstein-Friesian. Cuesta (2000) found an elasticity of concentrates similar to the one estimated in this study using a sample in which all cows were Holstein-Friesian.

It should be noted that the output elasticity related to labor was found to be negative, but not significant, in another analysis of the productivity of Spanish dairy farms (Cuesta, 2000). In explaining this result, Cuesta (2000) argued that "... farms in the sample are familyrun farms and the labor variable could be reflecting a disguised unemployment problem." However, in the present study, the elasticity with respect to labor $\left(\beta_{1}\right)$ was found to be positive $(P<0.05)$. The change in this output elasticity could be due to the changes in the Spanish dairy sector from 1987 to 1991, which was the sampling period in Cuesta (2000), up until the sampling period in the present study. The number of dairy farms in Spain decreased from 206,750 in 1990 to 51,030 in 2003 (Eurostat, 2010). Thus, it is expected that only the most professional farms remain in the market and these farms may not fit the profile of farms studied by Cuesta (2000).

The average technical efficiency found in the present study was $90 \%$. This result shows that, on average, farmers produced only $90 \%$ of the maximum output attainable with their input endowment. The technical efficiency of farms in the sample was close to that reported by Lawson et al. (2004) who found a technical efficiency score of $93 \%$, and somewhat higher than those of Hallam and Machado (1996), Bravo-Ureta and Rieger (1991), or Cuesta (2000), which range between
68 and $85 \%$ for Portuguese, US, and Spanish farms, respectively. Again, if only the best farms remain in business, it is expected that the average technical efficiency would increase during this period of adjustment in the Spanish dairy sector.

Solving equation [3] allows a first evaluation of the effect of genetics on milk production. The obtained results imply that for an efficient farm using an input endowment equal to the sample mean an increase of 1 $\mathrm{kg}$ in the GI of the herd, maintaining other inputs constant, would cause an increase in production in a $95 \%$ confidence interval between 0.75 and $1.5 \mathrm{~L}$ of milk per cow per year. However, the increase in milk production would range only from 0.67 to $1.4 \mathrm{~L}$ of milk per cow for a farm with average technical efficiency.

A more consistent evaluation of the contribution of genetics to milk production should take into account the effect of genetics on feed intake. Solving equations [7] and [8] with least squares indicated that a 1-kg increase in GI would have caused, on average, farmers to increase forage expenses and concentrates by $€ 0.09$ and $0.70 \mathrm{~kg}$ per cow, respectively. Thus, the expected feed intake for a cow with a genetic merit equal to $z^{99}$ consists of $3,611 \mathrm{~kg}$ of concentrates and €532 in forage expenses. On the other hand, a cow with genetic merit equal to $z^{04}$ would have consumed an average of 3,838 $\mathrm{kg}$ of concentrates and $€ 560$ in forage, which at the herd level, corresponds to a consumption of $153,500 \mathrm{~kg}$ of concentrates $\left(x_{3}^{04}\right)$ and forage by a value of $€ 22,398$ $\left(x_{4}^{04}\right)$. If the genetic level were to remain at $z^{99}$, the farmer would use $144,438 \mathrm{~kg}$ of concentrates $\left(x_{3}^{99}\right)$ and would spend $€ 21,275$ on forage $\left(x_{4}^{99}\right)$.

Once the feed intake corresponding to each GI was calculated, the results were plugged into equation [9] to determine the contribution of genetic progress to milk production over the entire period. It was calculated that the increase in GI from $z^{99}$ to $z^{04}$ would have increased farm production by $23,696 \mathrm{~L} / \mathrm{yr}$ if the farm were fully efficient. On the other hand, this genetic progress would increase milk production by 21,226 L for a farm with average technical efficiency.

The effect of the genetic progress on GM was also calculated by substituting the results obtained from equation [9] into equation [10]. Table 5 reports GM of average and frontier farms depending on the overall genetic merit of the herd and the GM increase due to the genetic progress during the period. Table 5 shows that, for an optimally managed farm, €4,457 of their total GM in $2004(€ 41,691)$ was due to genetic progress 
Table 5. Dairy farm gross margin (GM) in 2004 and GM if genetic index takes 1999 value

\begin{tabular}{lccc}
\hline Item & GM in & GM with 1999 & GM due to \\
genetic index $(€)$ & genetic progress $(€)$ \\
\hline Frontier farm & $2004(€)$ & 37,234 & 4,457 \\
Average farm & 41,691 & 26,601 & 3,661 \\
\hline
\end{tabular}

accumulated since 1999. Thus, the genetic progress over this period would lead to an increase in profits of $12 \%$ compared with what the farm would have obtained if GI had remained constant at the 1999 level (€37,234). It is worth noting that to achieve a similar increase in GM, a $5 \%$ increase in income from milk sales would be necessary if genetics were held constant at the 1999 level.

From Table 5 it is possible to evaluate the importance of optimal management in exploiting the genetic quality of the herd. An average managed farm would extract only $€ 3,661$ from the genetic progress during that period. The increase in GM due to genetics would be $€ 796$ greater for a technically efficient farm than for a farm with average technical efficiency, which implies a $22 \%$ higher return on genetics.

\section{CONCLUSIONS}

An economic model of farm production was used to evaluate the effect of genetic progress on profits of Spanish farmers. The empirical analysis confirms that genetic progress can be considered a powerful tool for increasing farm profitability, especially in a context where milk prices are expected to remain low in the future. The use of a stochastic production frontier approach allowed an evaluation of the importance of optimal management in extracting the maximum return on genetics. The results revealed that Spanish agricultural extension as well as other services might play an important role in helping farmers to exploit the potential advantages of genetic progress by improving management quality.

\section{REFERENCES}

Aigner, D., K. Lovell, and P. Schmidt. 1977. Formulation and estimation of stochastic frontier production function models. J. Econom. 6:21-37.

Alvarez, A., and C. Arias. 2004. Technical efficiency and farm size: A conditional analysis . Agric. Econ. 30:241-250.

Bravo-Ureta, B. E., and L. Rieger. 1991. Dairy farm efficiency measurement using stochastic frontier and neoclassical duality. Am. J. Agric. Econ. 73:421-428.
Cabrera, V. E., D. Solís, and J. del Corral. 2010. Determinants of technical efficiency among dairy farms in Wisconsin. J. Dairy Sci. 93:387-393.

Chambers, R. G. 1988. Applied Production Analysis: A Dual Approach. Cambridge University Press, Cambridge, UK.

Christensen, L., D. Jorgenson, and L. Lau. 1973. Transcendental logarithmic production frontiers. Rev. Econ. Stat. 55:28-45.

Commission of the European Communities. 2002. Communication from the Commission to the Council and the European Parliament: MidTerm Review of the Common Agricultural Policy. COM 394/2. European Union, Brussels, Belgium.

Commission of the European Communities. 2009. Communication from the Commission to the Council: Dairy Market Situation. COM 385/4. European Union, Brussels, Belgium.

CONAFE. 2009. Informe de índices genéticos por categoría. CONAFE, Madrid, Spain.

Cuesta, R. A. 2000. A production model with firm-specific temporal variation in technical inefficiency: With application to Spanish dairy farms. J. Prod. Anal. 13:139-158.

Eurostat. 2010. Structure of agricultural holdings by region, main indicators. http://epp.eurostat.ec.europa.eu/portal/page/portal/ agriculture/data/database

Gengler, N., G. R. Wiggans, and J. R. Wright. 1999. Animal model genetic evaluation of type traits for five dairy cattle breeds. J. Dairy Sci. 82:1350.

Hallam, D., and F. Machado. 1996. Efficiency analysis with panel data: A study of Portuguese dairy farms. Eur. Rev. Agric. Econ. 23:79-93.

Heringstad, B., Y. M. Chang, D. Gianola, and G. Klemetsdal. 2003. Genetic analysis of longitudinal trajectory of clinical mastitis in first-lactation Norwegian cattle. J. Dairy Sci. 86:2676-2683.

Kumbhakar, S., and C. A. K. Lovell. 2000. Stochastic frontier analysis. Cambridge University Press, New York, NY.

Lawson, L. G., J. Bruun, T. Coelli, J. F. Agger, and M. Lund. 2004. Relationships of efficiency to reproductive disorders in Danish milk production: A stochastic frontier analysis. J. Dairy Sci. $87: 212-224$.

SADEI. 2009. Las explotaciones ganaderas Asturianas. http://www. sadei.es

Steine, G., D. Kristofersson, and A. G. Guttormsen. 2008. Economic evaluation of the breeding goal for Norwegian red dairy cattle. J. Dairy Sci. 91:418-426.

Stevenson, R. E. 1980. Likelihood functions for generalised stochastic frontier estimation. J. Econom. 13:57-66.

Tauer, L. W. 2001. Efficiency and competitiveness of the small New York dairy farm. J. Dairy Sci. 84:2573-2576.

Veerkamp, R. F. 1998. Selection for economic efficiency of dairy cattle using information on live weight and feed intake: A review. J. Dairy Sci. 81:1109-1119.

Weersink, A., W. Howard, J. Dekkers, and M. Lohuis. 1991. Sire selection decisions and farm profitability relationships for Ontario dairy farmers. J. Dairy Sci. 74:3994-4001. 